\title{
Assessing Patient Safety Culture in the Hospital: a Pilot Study Using a Modified Manchester Patient Safety Framework (MaPSaF)
}

\section{Arum Astika*

\begin{tabular}{l}
\hline I N D E X I N G \\
\hline Keywords: \\
Patient Safety Culture; \\
Patient Safety Culture \\
Tool; \\
MaPSaF;
\end{tabular}

*Correspondence Author: arumastika.md@gmail.com

*Raudah Primary Clinic, Depok, Indonesia

Kata Kunci:

Budaya Keselamatan

Pasien;

Alat Kultur Keselamatan

Pasien;

$\mathrm{MaPSaF}$;

\begin{abstract}
A B S T R A C T
The aim of this study was to modify and determine the dimensions and themes of the patient safety culture tool by MaPSaF. This study was a qualitative design with study literature approach. The result of this study was MaPSaF composed of 10 dimensions of patient safety culture with 24 aspects which contain with the statements in each theme. The dimensions are commitment to overall continuous improvement, priority given to safety, system errors and individual responsibility, recording incidents and best practice, evaluating incidents and best practice, learning and affecting change, communication about safety issues, personnel management and safety issues, staff education and training, and teamwork. The aspects are the commitment to improvement, audit, policies, priority of patient safety, risk management system, implementation of patient safety, the cause of the incident, patient safety culture, reporting feeling and system, data analysis, the focus and result of investigation, incidents learning, the people in deciding of change, communication about patient safety between staff, patient or both, share the information, supporting the staff, training needs and purposes, team structure, the flow of information and sharing.
\end{abstract}

Article history: Received 08 Sep 2017; Revised 09 Oct 2017; Accepted 15 Nov 2017

(C) 2017 JMMR. All rights reserved

\section{INTRODUCTION}

In this era patient safety is one of the many critical issues in hospitals that often published and became a focus in Indonesia and international. Patient safety in the hospital then becomes an important issue because of the many cases of medical errors that occur in many countries. ${ }^{1}$ Patient safety incidents are errors made by people at the frontline of operations (eg, in the case of medication administration, this is most likely to be a nurse). ${ }^{2}$
Each year in the United States nearly 100,000 patients who were hospitalized died because of medical error, other than that the research also proved that the deaths due to medical injury $50 \%$ of which are preventable. ${ }^{3}$

Institute of Medicine (IOM) United States in 2000 published the report "To Err is Human, Building to Safer Health System" which states that hospitals in Utah and Colorado found adverse event was $2.9 \%$ and $6.6 \%$ died, while in New York found adverse event was $3.7 \%$ and $13.6 \%$ died. Furthermore, mortality due to adverse event in 
hospitalized patients in the United States totaled 33.6 million per year range $44000-98000$ people. In the other hand, the publication of the WHO in 2004 declared adverse event was in range of $3.2 \%-16.6 \%$ at the hospitals in various countries such as US, UK, Denmark and Australia. ${ }^{3,4}$ So, the IOM highlighted the importance os safety culture by starting that "health care organizations must develop a culture of safety such that an organization's care processes and workforce are focused on improving the reability and safety of care for patients". ${ }^{3}$

There are two fundamental assumptions underlying much of the safety culture study: (1) a positive safety culture is associated with improved safety performance 5 and (2) it is possible to improve the culture of an organization. $^{7}$ To date, most patient safety study has focused on hospital care and tools to measure and maturity level of safety culture in hospitals have been developed and tested. ${ }^{8,9}$ Although we know that patient safety is a concern in health care settings, study on how to improve patient safety in health care remains underdeveloped. ${ }^{9,10}$ There are no tools designed to assess safety culture in Indonesia hospitals.

However, a United Kingdom group has developed a tool-the Manchester Patient Safety Framework (MaPSaF) - to assess and maturity safety culture in UK Primary Care Trusts. 5 In this study we aimed to modify the $\mathrm{MaPSaF}$ and determine the dimensions and aspects of the patient safety culture By Mapsaf as Form of Questionnaire Tool Development. Development of the Manchester Patient Safety Framework (MaPSaF) Several instruments with differing characteristics are available to assess the generic concept of patient safety culture, which is part of organizational culture.

In recent years some specific instruments have been developed to measure the patient safety culture, such as Hospital Survey on Patient Safety Culture (HSOPSC) from the Agency for Healthcare Research and Quality (AHRQ) in the USA, Manchester Patient Safety Assessment Framework (MaPSaF) from the University of Manchester in the UK, Safety Attitudes Questionnaire from the University of Texas/Johns Hopkins University in the USA. ${ }^{11}$ In addition, a number of other instruments used were commented on, but not directly recommended. These instrument tend to be based on surveys of the organization's culture, emphasising individual attitudes and opinions, share beliefs, values and assumption. Suggest patient safety research has focused on hospital care and tools to measure and strengthen safety culture in hospitals have been developed and tested. ${ }^{12}$
In order to improve safety culture, it is essential to base changes on a framework of safety culture that takes into account the multidimensional nature of the concept. ${ }^{11}$ In line with this idea, Parker et al. looked to the theoretical typology of organization culture based on James Reason's adaption of the Westrum model. ${ }^{13,14,15}$ This typology distinguishes between cultures based on how information is handled, and identifies three different levels of organizational culture - pathological, bureaucratic and generative. In addition to detailing the style of information processing in a unit, the typology references the role of leaders who shape the unit's culture through their symbolic actions and provide rewards and punishments that communicate what they feel is important; these then influence the views of the workforce. ${ }^{16}$ Westrum suggests that good information flow and processing has important effects on patient safety (such as good teamwork), and that an open and generative culture means a better uptake of innovations and response to danger signals. ${ }^{15}$ First adapted this framework for an empirical study in the petroleum industry, extending the number of levels of safety culture to five and applying them to a range of dimensions. ${ }^{11}$ This resulted in a normative framework identifying "good" or "bad" safety cultures and illustrating how safety culture could be improved. The framework also facilitated the comparison of organizational cultures and subcultures. ${ }^{17}$ This work was then expanded to the healthcare field with the development of the Manchester Patient Safety Framework. This framework was developed through extensive reviews of the literature in healthcare and consultations with experts in the field.

The form that MaPSaF takes is informed by two key points. The first is that organizations do not either have, or not have a safety culture. Rather they develop a safety culture over time, passing through several stages of development. The second key point is that safety culture is not a separate tangible aspect of the organization, but rather an emergent property that manifests itself in all safety related aspects of the organization. Therefore, a useful safety culture assessment tool ought to consider multiple aspects, or dimensions, of safety culture, separately, and not simply provide one overall "score" for safety culture, which might disguise a complex picture of relative strengths and weaknesses. In other words, in order to develop an understanding of the subtle and complex nature of safety culture in healthcare organizations, a multidimensional measurement tool is needed. ${ }^{18}$

MaPSaF handles both of these points, allowing users to consider both the multi-dimensional nature, and the stage 
of development of the safety culture in their organization. In the version for use in primary care settings, the nine dimensions of safety culture covered are as follows : (1) overall commitment to quality, (2) priority given to patient safety, (3) perceptions of the causes of patient safety incidents and their identification, (4) investigating patient safety incidents, (5) organizational learning following a patient safety incident, (6) communication about safety issues, (7) personnel management and safety issues, (8) staff education and training about safety issues, (9) team working around safety issues. But in MaPSaF-acute care or hospital there is little difference in dimensions, which consists of 10 dimensions of patient safety culture, with the added dimension "system error and individual responsibility".

\section{RESEARCH METHOD}

This study focused on the development of patient safety culture tool. This is a qualitative research that used experts interview and literature study approach. The basis of this study was to establish the recent culture of organization level 8, so therefore the baseline is MaPSaF (Manchester Patient Safety Framework) from NPSA (National Patient Safety Agency).

The Manchester Patient Safety Framework (MaPSaF) is a tool to help NHS organization and healthcare teams assess their progress in developing a safety culture. MaPSaF uses critical dimensions of patient safety and for each of these describes five levels of increasingly mature organizational safety culture. The dimensions relate to areas where attitudes, values and behaviors about patient safety are likely to be reflected in the organization's working practices. For example, how patient safety incidents are investigated, staff education, and training in risk management.

MaPSaF can be used in many ways, for example: to facilitate reflection on patient safety culture, to stimulate discussion about the strengths and weaknesses of the patient safety culture, to reveal any differences in perception between staff groups, to help understand how a more mature safety culture might look, to help evaluate any specific intervention needed to change the patient safety culture. These can be applied at organizational or team level. $^{9}$

Methodological steps of this study was as follows: (1) determine the culture of patient safety as a variable that the tool will be developed, (2) to translate the MaPSaF by swore translator in the Language Training Centre, University of Muhammadiyah Yogyakarta, (3) formulated statements points for each dimension of patient safety culture that exist in the MaPSaF as an assessment tool, (4) validating the theoretical to the group of expert panelists as judges to adjust the meaning of the translation and select statement items of dimensional of patient safety culture, (5) conducting a pilot study of the tool through test re-test approach, (6) measure the reability stability obtained by test re-test result, (7) confirm to the experts to repair the toolson the unreliable statements.

\section{RESULT AND DISCUSSION}

Many of the experimental researches on patient safety culture in Indonesia using HSOPSC tool from AHRQ that has good validity value, but it can't explain the level of maturity of patient safety culture. At the beginning of the study, the results of discussions with experts chose a $\mathrm{MaPSaF}$ tool as a variable tool will be developed. This was done because MaPSaF has the maturity level of patient safety culture owned by hospital, which was divided into five levels: pathological, reactive, bureaucratic, proactive and generative ${ }^{8}$ (Table 1). The presence the cultural level can be used to follow-up on the development of patient safety culture, as well as to benchmark among hospitals in Indonesia, for example, hospitals that have been accredited plenary but patient safety culture is still low. 
Table 1. The description of patient safety culture level

\begin{tabular}{ll}
\hline \multicolumn{1}{c}{ Maturity level } & \multicolumn{1}{c}{ Description level } \\
\hline A - Pathological & Why do we need to waste our time on patient safety issues? \\
B - Reactive & We take patient safety seriously and do something when we have an incident. \\
C - Bureaucratic & We have systems in place to manage patient safety. \\
D - Proactive & We are always on the alert/thinking about patient safety issues that might emerge. \\
E - Generative & Managing patient safety is an integral part of everything we do. \\
\hline
\end{tabular}

Furthermore, the translation result of MaPSaF (Table 2 \& 3) was used to develop statement points of patient safety culture. Frameworks in MaPSaF was displayed in the form of a matrix briefly described the hospital at every level of patient safety culture are spelled out into 10 dimensions compiled by the research team of the University of Manchester consisting of psychologists, researchers in the field of health and other health professionals. Dimensions of patient safety culture by MaPSaF are: (1) commitment to overall continuous improvement, (2) priority given to patient safety, (3) system error and individual responsibility, (4) recording incidents and best practice, (5) evaluating incident and best practice, (6) learning and effecting change, (7) communication about safety issues, (8) personnel management and safety issues, (9) staff education and training, (10) team working.

Tabel 2. Translation description of the dimensions of patient safety

\begin{tabular}{ll}
$\begin{array}{c}\text { Dimension of patient safety } \\
\text { culture }\end{array}$ & Description \\
\hline $\begin{array}{l}\text { Commitment to overall } \\
\text { continuous improvement }\end{array}$ & $\begin{array}{l}\text { How much is invested in developing the quality agenda? What is seen as the main purpose of } \\
\text { policies and procedures? What attempts are made to look beyond the organization for collaboration } \\
\text { and innovation? }\end{array}$
\end{tabular}

Priority given to patient safety How seriously is the issue of patient safety taken within the organization? Where does responsibility lie for patient safety issues?

System errors and individual responsibility

Recording incidents and best practice

Evaluating incidents and best practice

Learning and effecting change

Communication about safety issues

Personnel management and safety issues

Staff education and training

Team working
What sort of reporting systems are there? How are reports of incidents received? How are incidents viewed - as an opportunity to blame or improve?

Who investigates incidents and how are they investigated? What is the aim of recording the incident?

How are any incidents evaluated? What recognition is there of safe practice? How is the resultant data used?

What happens after an event? What mechanisms are in place to learn from the incident? How are changes introduced and evaluated?

What communication systems are in place? What are their features? What is the quality of record keeping to communicate about safety like?

How are safety issues managed in the workplace? How are staff problems managed? What are the recruitment and selection procedures?

How, why and when are education and training programs about patient safety developed? What do staffs think of them?

How and why are teams developed? How are teams managed? How much team working is there around patient safety issues? 
Table 3. System errors and individual responsibility

System errors and individual responsibility

\begin{tabular}{|c|c|}
\hline Maturity level & Description \\
\hline Pathological & $\begin{array}{l}\text { Incidents are seen as 'bad luck' and outside the organization's control, occurring as a result of staff errors or patient } \\
\text { behavior. There is a strong blame culture with individuals subjected to victimization and disciplinary action. }\end{array}$ \\
\hline Reactive & $\begin{array}{l}\text { The organization sees itself as a victim of circumstances. Individuals are seen as the cause and the solution is } \\
\text { retraining and punitive action. When incidents occur there is no attempt to support those involved, including the } \\
\text { patients and their relatives. }\end{array}$ \\
\hline Bureaucratic & $\begin{array}{l}\text { There is a recognition that systems contribute to incidents and not just individuals. The organization says that it has } \\
\text { an open and fair culture but it is not perceived in that way by staff. Being open/open disclosure protocols have been } \\
\text { written to ensure that staff and patients/carers receive support following an incident do exist, but they are not widely } \\
\text { known about or used. }\end{array}$ \\
\hline Proactive & $\begin{array}{l}\text { It is accepted that incidents are a combination of individual and system faults. The organization has an open, fair and } \\
\text { collaborative culture. Following a patient safety incident, a systems analysis is carried out and used to make } \\
\text { decisions about the relative contribution of systems factors and the individual, e.g. the Incident Decision Tree. This } \\
\text { process informs decisions about staff suspensions and so there is a consistent and fair approach to dealing with staff } \\
\text { issues following incidents. The organization is also open and honest with patients and/or their carers when a patient } \\
\text { safety incident occurs that led to severe harm or death, but does not discuss all types of incidents. }\end{array}$ \\
\hline Generative & $\begin{array}{l}\text { Organizational and system failures are noted and staff are also fully aware of their own personal accountability in } \\
\text { relation to errors and of their empowerment to report them. Integrated systems enable patient safety incidents, } \\
\text { complaints and litigation cases to be analyzed together. Staff, patients and relatives are actively involved and } \\
\text { supported from the time of the incident. The organization has a high level of openness and trust. The organization is } \\
\text { also open and honest with patients and/or their carers about all types of patient safety incidents, irrespective of the } \\
\text { level of harm caused. }\end{array}$ \\
\hline
\end{tabular}

The next step was the elaboration of the aspect statements points for each dimension of patient safety culture, there are 24 aspects (Table 4), namely: (1) commitment to improvement, (2) inspection/auditing, (3) SOP and policies, (4) priority given to patient safety (5) risk management system, (6) patient safety practices, (7) blame culture and punishment, (8) reporting system and usage, (9) staff feeling on reporting the incident, (10) data analysis,
(11) focus of investigation, (12) results/output of investigation, (13) learning from safety incidents, (14) who decide the change after the incident, (15) communication about patient safety, (16) sharing the information, (17) communicating with patients about safety, (18) do the staffs feel supported?, (19) training needs, (20) training resources, (21) training purpose, (22) team structure, (23) the role of team member, (24) the flow of information and sharing.

Tabel 4. Dimension and aspect of patient safety culture

\section{Dimension of patient safety culture}

Commitment to overall continuous improvement

Priority given to patient safety

System errors and individual responsibility

Recording incidents and best practice

Evaluating incidents and best practice

\section{Aspects /Themes}

1) commitment to improvement
2) inspection / audit
3) SOP and policies
4) priority given to patient safety
5) risk management system
6) implementation of patient safety
7) blame culture and punishment
8) reporting system and usage
9) staff feeling on reporting the incident
10) data analysis
11) focus of investigation
12) results/ output of investigation




\begin{tabular}{|c|c|c|c|c|}
\hline Dimension of patient safety culture & \multicolumn{4}{|c|}{ Aspects /Themes } \\
\hline \multirow[t]{2}{*}{ Learning and effecting change } & 13) & \multicolumn{3}{|c|}{ learning from safety incidents } \\
\hline & 14) & \multicolumn{3}{|c|}{ who decide the change after the incident } \\
\hline \multirow[t]{3}{*}{ Communication about safety issues } & 15) & \multicolumn{3}{|c|}{ communication about patient safety } \\
\hline & 16) & \multicolumn{3}{|l|}{ sharing the information } \\
\hline & 17) & \multicolumn{3}{|c|}{ communicating with patients about safety } \\
\hline Personnel management and safety issues & 18) & \multicolumn{3}{|c|}{ do the staffs feel supported? } \\
\hline \multirow[t]{3}{*}{ Staff education and training } & 19) & \multicolumn{3}{|l|}{ training needs } \\
\hline & 20) & \multicolumn{3}{|l|}{ training resources } \\
\hline & 21) & \multicolumn{3}{|l|}{ training purpose } \\
\hline \multirow[t]{3}{*}{ Team working } & 22) & \multicolumn{3}{|l|}{ team structure } \\
\hline & 23) & \multicolumn{3}{|c|}{ the role of team member } \\
\hline & 24) & \multicolumn{3}{|c|}{ the flow of information and sharing } \\
\hline $\begin{array}{l}\text { The composition of instrument stater } \\
\text { validated by experts as the construct validit } \\
\text { of some statement have been selected which } \\
\text { the MaPSaF translation. The adjustment of }\end{array}$ & $\begin{array}{l}\text { ents was then } \\
\text { The meaning } \\
\text { s suitable with }\end{array}$ & \multicolumn{3}{|c|}{$\begin{array}{l}\text { meaning of research was expected to help respondents to } \\
\text { understand and comprehend the contents of these } \\
\text { instruments in the form of a questionnaire, for example for } \\
3^{\text {rd }} \text { dimension (Table 5). }\end{array}$} \\
\hline \multicolumn{5}{|c|}{ Tabel 5. Example of MaPSaF Instrumen Development } \\
\hline Pathological (A) & Reactive (B) & Burauecratic (C) & Proactive (D) & Generative (E) \\
\hline \multicolumn{5}{|c|}{ Dimension 8 . Personnel management and safety issues } \\
\hline $\begin{array}{l}\text { Staff feel } \\
\text { unsupported, as } \\
\text { poor health and } \\
\text { attendance records } \\
\text { are seen as } \\
\text { diplinary matters. }\end{array}$ & $\begin{array}{l}\text { Staff duties are } \\
\text { noticed when } \\
\text { there are } \\
\text { incidents. }\end{array}$ & $\begin{array}{l}\text { Personel } \\
\text { management } \\
\text { procedures are seen } \\
\text { as a tool to control } \\
\text { staff. }\end{array}$ & $\begin{array}{l}\text { Management } \\
\text { designed } \\
\text { support for } \\
\text { staff needs. } \\
\text { Health of the } \\
\text { staff paid } \\
\text { attention. }\end{array}$ & $\begin{array}{l}\text { Staffing management } \\
\text { reflects and } \\
\text { deliberates on staff } \\
\text { competencies, } \\
\text { ssupervises and } \\
\text { mentoring }\end{array}$ \\
\hline
\end{tabular}

We carried out a test instrument to 3 respondents working in excellent accredited hospital. Tests performed twice on the same respondents with different day. The results of the pilot test of the instrument was used as stability reliability test used was re-test. The result are different answers from three different respondents $100 \%$ on 3 aspects contained in the instrument MaPSaF (Table 6). These aspects are (1) patient safety practises, (2) communicating with patients about safety and (3) the flow of information and sharing.

Table 6 Test re-test result

\begin{tabular}{|c|c|c|c|c|c|c|c|c|c|c|c|c|c|c|c|c|c|c|c|c|c|c|c|c|c|c|c|c|c|c|c|c|}
\hline \multicolumn{11}{|c|}{ Respondent A } & \multicolumn{11}{|c|}{ Respondent B } & \multicolumn{11}{|c|}{ Respondent C } \\
\hline & \multicolumn{5}{|c|}{ Day I } & \multicolumn{5}{|c|}{ Day II } & & \multicolumn{5}{|c|}{ Day I } & \multicolumn{5}{|c|}{ Day II } & & \multicolumn{5}{|c|}{ Day I } & \multicolumn{5}{|c|}{ Day II } \\
\hline & $\mathrm{E}$ & $\mathrm{D}$ & $\mathrm{C}$ & $\mathrm{B}$ & $\mathrm{A}$ & $\mathrm{E}$ & $\mathrm{D}$ & $\mathrm{C}$ & B & $\mathrm{A}$ & & $\mathrm{E}$ & $\mathrm{D}$ & $\mathrm{C}$ & B & $\mathrm{A}$ & $E$ & $\mathrm{D}$ & $\mathrm{C}$ & B & A & & $\mathrm{E}$ & $\mathrm{D}$ & $\mathrm{C}$ & $\mathrm{B}$ & $\mathrm{A}$ & $\bar{E}$ & $\mathrm{D}$ & $\mathrm{C}$ & B & $\mathrm{A}$ \\
\hline 1 & & + & & & & & + & & & & 1 & & + & & & & & + & & & & 1 & & + & & & & & + & & & \\
\hline 2 & & + & & & & & + & & & & 2 & & + & & & & & + & & & & 2 & & + & & & & & + & & & \\
\hline 3 & & + & & & & & + & & & & 3 & & + & & & & & + & & & & 3 & & + & & & & & + & & & \\
\hline 4 & + & & & & & + & & & & & 4 & + & & & & & + & & & & & 4 & + & & & & & + & & & & \\
\hline
\end{tabular}




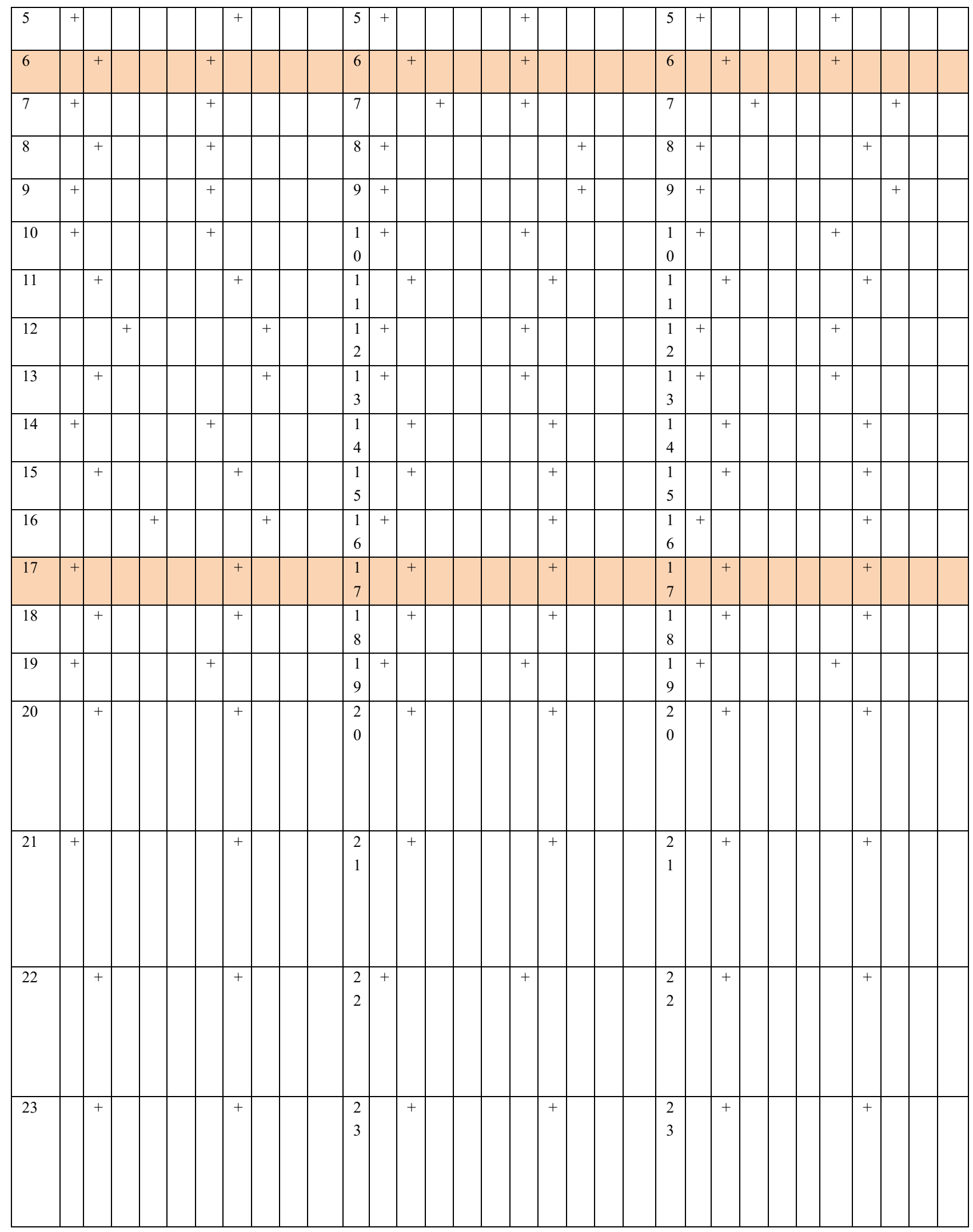




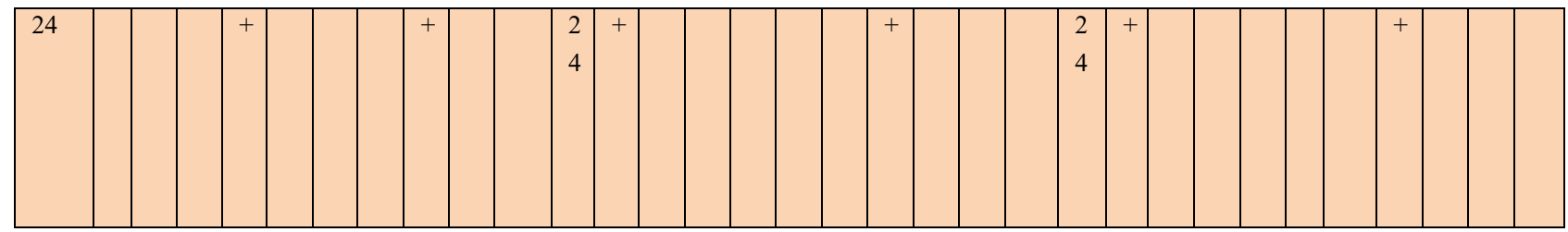

Then the next step was to correct the statement which is not realiable by submitting to the expert to review again the meaning of the context of each description level of patient safety culture, by replacing the words on the unreliable statement (table 7).

Table 7. Last Revison

\begin{tabular}{|c|c|c|}
\hline & Before & After \\
\hline \multicolumn{3}{|c|}{ Priority is given to patient safety } \\
\hline \multicolumn{3}{|c|}{ Aspect 6 . Implementation of patient safety } \\
\hline Generative & $\begin{array}{l}\text { Implementation of patient safety is inherent to all } \\
\text { activities in the hospital. }\end{array}$ & $\begin{array}{l}\text { Implementation of patient safety is inherent to all activities } \\
\text { in the hospital. }\end{array}$ \\
\hline Proactive & All staff involved in patient safety & $\begin{array}{l}\text { All staff involved in patient safety, but not entirely reflected } \\
\text { in the activity of hospital }\end{array}$ \\
\hline Bureaucratic & $\begin{array}{l}\text { Implementation of the patient safety fail to respond } \\
\text { the complexity of the problems that occur. }\end{array}$ & $\begin{array}{l}\text { Implementation of patient safety is the responsibility of } \\
\text { individual in the organization. }\end{array}$ \\
\hline Reactive & $\begin{array}{l}\text { Patient safety is discussed when there is an incident } \\
\text { happens. Patient safety carries the staff security but } \\
\text { not for patient. }\end{array}$ & $\begin{array}{l}\text { Patient safety is discussed when there is an incident. Patient } \\
\text { safety carried out for staff security, not for patient safety. }\end{array}$ \\
\hline Pathological & $\begin{array}{l}\text { Staffs are less concerned about patient safety, } \\
\text { because it is covered by insurance }\end{array}$ & $\begin{array}{l}\text { Staffs are less concerned about the safety of patients, } \\
\text { because according to their existing insurance coverage. }\end{array}$ \\
\hline \multicolumn{3}{|c|}{ Communication about safety issues } \\
\hline \multicolumn{3}{|c|}{ Aspect 17. Communication about patient safety to patients } \\
\hline \multirow[t]{2}{*}{ Generative } & & . \\
\hline & Good internal and external communication & $\begin{array}{l}\text { Transparency of patient safety incident and involved the } \\
\text { patients in the risk management. }\end{array}$ \\
\hline \multirow[t]{2}{*}{ Proactive } & & . \\
\hline & $\begin{array}{l}\text { Communicating patient safety to patients and } \\
\text { families/visitors of hospital. }\end{array}$ & $\begin{array}{l}\text { Effective communication about patient safety issues } \\
\text { involving the patient and community groups. }\end{array}$ \\
\hline Bureaucratic & $\begin{array}{l}\text { Informations about patient safety are not utilized } \\
\text { effectively. }\end{array}$ & $\begin{array}{l}\text { The issue of patient safety that comes from patients not } \\
\text { used effectively. }\end{array}$ \\
\hline Reactive & One-way communication & $\begin{array}{l}\text { Information on patient safety issues from the patients were } \\
\text { not followed up by the hospital. }\end{array}$ \\
\hline \multirow[t]{2}{*}{ Pathological } & Patients receive information when legally regulated. & \\
\hline & & $\begin{array}{l}\text { Patients have the opportunity of communication about the } \\
\text { incident if it involved the law. }\end{array}$ \\
\hline \multicolumn{3}{|l|}{ Team working } \\
\hline \multicolumn{3}{|c|}{ Aspect 24. The flow of information and sharing } \\
\hline Generative & $\begin{array}{l}\text { The team is open to sharing information with other } \\
\text { parties (local, national and international) }\end{array}$ & $\begin{array}{l}\text { The team is fully open to share with others from various } \\
\text { local organizations, national, and international levels. }\end{array}$ \\
\hline Proactive & $\begin{array}{l}\text { The team is open to share the information included } \\
\text { on outsiders. }\end{array}$ & $\begin{array}{l}\text { The team is open to share information with outside parties } \\
\text { with few restrictions. }\end{array}$ \\
\hline Bureaucratic & $\begin{array}{l}\text { The mechanisms that regulate the information is not } \\
\text { effective. }\end{array}$ & $\begin{array}{l}\text { The mechanisms that regulate the communication already } \\
\text { exists, but is not effective. }\end{array}$ \\
\hline Reactive & $\begin{array}{l}\text { The flow of information continues in accordance } \\
\text { with the appropriate level of the hierarchy of their } \\
\text { respective interests }\end{array}$ & $\begin{array}{l}\text { The flow of information flowing to team members after the } \\
\text { incident. The team is defensive. }\end{array}$ \\
\hline Pathological & The team members keep information & $\begin{array}{l}\text { Information is shared among the team members, but still } \\
\text { keep each other. }\end{array}$ \\
\hline
\end{tabular}


The results provided by this tool allow decisionmakers to understand where they are doing well, and to celebrate these successes, as well as where there remain opportunities to enhance the safety culture. This information is conveyed through dimension summaries and graphic profiles that link to an overarching framework for safety maturity. The questionnaire provides a summary of safety culture dimensions, versus a copious amount of information from a large number of individual survey questions. With the MaPSCAT, decision-makers can examine their scores at these levels and refer back to the framework to see what types of statements and actions are aligned to higher levels of culture. It is important to provide results in a way that will ensure their uptake. this format may enhance decision makers' ability to do so. This unique way of studying and presenting the results may make MaPSCAT more appealing to decision-makers than previous tools as MaPSCAT helps to provide ideas and direction for moving the culture forward.

\section{Using The Modified MaPSaF Tool}

This questionnaire aims to ask respondent's opinions about patient safety issues in the unit and hospital where respondents work. To solve all the questions in this survey takes approximately 15-20 minutes. This questionnaire is not a test with right or wrong answers, most importantly respondents answered honestly according to the opinion and condition of respondents. This questionnaire consists of 10 dimensions, where each dimension has several different aspects (Table 8). Each aspect is considered a question answered by the respondent by filling out a statement in accordance with the reality of the field/hospital, not an answer that describes the situation expected by the respondent. This questionnaire can be used optimally if all questions are answered. Grading depends on the statement chosen by the respondent on the questionnaire, if the researcher wants to avoid the bias then the researcher makes the questionnaire with the answer column randomly. The coding of answers is as follows: (1) Pathological: A, (2) Reactive: B, (3) Bureaucrative: C. (4) Proactive: D, (5) Generative: E. Then after data collected, form the table, then calculate the data with existing computer software by counting the number of respondents in each category of maturity level on each aspect. The dominant number is the final result of the maturity level in every aspect. Then proceed by changing the number in percentage form. Then calculate the average number of answers at each level of maturity in each dimension. The dominant/highest average result is the end result of the maturity level in each dimension. (See the appendix 1.)

\section{CONCLUSION}

This study was conducted to assess the culture model of patient safety in the hospital as a health organization, called Manchester Patient Safety Framework (MaPSaF). $\mathrm{MaPSaF}$ tool include multiple dimensions of safety culture model, and five levels of development culture model of patient safety. The framework can be identified MaPSaF into 24 aspects within each dimension and modified by some statements as from of modfied questionnare. Some of these aspects are: (1) commitment to improvement, (2) inspection/auditing, (3) SOP and policies, (4) priority given to patient safety (5) risk management system, (6) patient safety practices, (7) blame culture and punishment, (8) reporting system and usage, (9) staff feeling on reporting the incident, (10) data analysis, (11) focus of investigation, (12) results/output of investigation, (13) learning from safety incidents, (14) who decide the change after the incident, (15) communication about patient safety, (16) sharing the information, (17) communicating with patients about safety, (18) do the staffs feel supported?, (19) training needs, (20) training resources, (21) training purpose, (22) team structure, (23) the role of team member, (24) the flow of information and sharing.

The tool can be used to identify the level of culture model of patient safety in hospital in Indonesia. It acknowledges the multidimensional and dynamic nature of the culture model, and allows the organization to assess their progress in developing the culture model of patient safety. This tool helps the health team in measuring their progress in making patient safety a major focus of their organization. This can help to determine the strengths and weaknesses the parts of the hospital so that the management or staff can improve culture of patient safety in the hospital in an effective manner.

\section{REFERENCE}

1. Institute of Medicine. 2000. To err is human: building a safer health system. USA. Available from: http://www.nationalacademies.org/hmd/ /media/Files/ Report\%20Files/1999/To-Err-is-

Human/To\%20Err\%20is\%20Human\%201999\%20\%2 Oreport\%20brief.pdf

2. Rebecca Lawton, 1 Rosemary R C McEachan. Sally J Giles. Reema Sirriyeh,1 Ian S Watt,3 John Wright. 2012. Development of an evidence-based framework 
of factors contributing to patient safety incidents in hospital settings: a systematic review. BMJ Qual Saf 2012;21:369e380. doi:10.1136/bmjqs-2011-000443.

3. Cahyono, S.B. 2008. Membangun Budaya Keselamatan Pasien dalam Praktik Kedokteran. Percetakan Kanisius. Yogyakarta.

4. Institute of Medicine. 2000. To Err is Human: Building a Safer Health System. USA. Avaliable from: http://www.nationalacademies.org/hmd/ /media/Files/ Report\%20Files/1999/To-Err-is-

Human/To\%20Err\%20is\%20Human\%201999\%20\%2 Oreport\%20brief.pdf

5. Depkes RI. 2006. Panduan Nasional Keselamatan Pasien di Rumah Sakit. Jakarta.

6. Clarke, S. 1999. Perception of organizational safety : Implication for the development of safety culture. Journal of Organizational Behavior 20 (2) : 185-186.

7. Guidenmund, F.W. 2000. The nature of safety culture : a review of theory and research. Safety Science 34 : 215-257.

8. Nieva V.F. \& Sorra J. 2003. Safety culture assessment: a tool for improving patient safety in healthcare organizations. Quality and Safety in Healthcare 12, ii17.

9. Singer S.J., Gaba D.M., Geppert J.J., Sinaiko A.D., Howard S.K. \& Park K.C. 2003. The culture of safety: results of an organization-wide survey in 15 California hospitals. Quality and Safety in Health Care 12, 112 118.

10. Weingart S., Farbstein K., Davis R. \& Phillips R. 2004. Using a multihospital survey to examine the safety culture. Joint Commission Journal on Quality and Safety 30, 125-132.

11. Parker D. 2006. Manchester Patient Safety Framework (MaPSaF) - Acute. National Patient Safety Agency. The University of Manchester. Available from: http://www.nrls.npsa.nhs.uk/resources/?entryid45=597 96

12. Wallis, K., \& Dovey, S. 2011. Assessing patient safety culture in New Zealand primary care: a pilot study using a modified Manchester Patient Safety Framework in Dunedin general practices. Journal of Primary Health Care, 3(1), 35-40

13. Singer S, Meterko M, Baker L, Gaba D, Falwell A, Rosen A. Workforce perceptions of hospital safety culture: Development and validation of the patient safety climate in healthcare organizations survey. Health Services Research. 2007 Oct; 42(5):19992021.
14. Parker, D., M. Lawrie and P. Hudson. 2006. A Framework for Understanding the Development of Organizational Safety Culture. Safety Science 44: 551-562.

15. Reason, J. 1997. Managing the Risks of Organisational Accidents. Ashgate: Aldershot.

16. Westrum, R. 1996. Human Factors Experts Beginning To Focus on Organizational Factors in Safety. ICAO Journal.

17. Westrum, R. 2004. A Typology of Organisational Cultures. Quality and Safety in Healthcare 13 (Suppl. II), ii22-ii27.

18. Lawrie, M., D. Parker and P. Hudson. 2006. Investigating Employee Perceptions of a Framework of Safety Culture Maturity. Safety Science 44: 259276.

19. Kirk S, Parker D, Claridge T, Esmail A, Marshall M. Patient safety culture in primary care: developing a theoretical frame-work for practical use. Qual Saf Health Care. 2007. 16: 313-320. 